\title{
CONSTRUÇÃO DE UMA INCUBADORA B.O.D. A PARTIR DE MATERIAIS RECICLADOS PARA USO EM ENSINO E PESQUISAS BOTÂNICAS
}

\author{
Mauro Sancearusso Bento* \\ Cristiano Pedroso-de-Moraes ${ }^{* *}$
}

\begin{abstract}
RESUMO: O presente trabalho contempla a construção de uma incubadora B.O.D., para uso em pesquisas na área de botânica, utilizando de materiais reciclados e alternativos, a fim de propiciar economia e ao mesmo tempo garantir a mesma funcionalidade dos equipamentos comerciais. Para verificação de funcionamento utilizou-se sementes de Alface (Lactuca sativa L.) germinadas no novo equipamento e no já existente no laboratório para fins comparativos e atestar a correta calibração da B.O.D. O trabalho apresenta detalhes da construção podendo ser utilizado para construção de mais aparelhos.
\end{abstract}

PALAVRAS-CHAVE: Incubadora; Reciclagem; Reutilização; Testes de germinação.

\section{BUILDING B.O.D INCUBATOR FROM RECYCLED MATERIAL FOR USE IN BOTANIC RESEARCH AND LECTURES}

\begin{abstract}
Current paper deals with the building of a BOD incubator for botanic research. Recycled and alternative materials were employed for cost saving while guaranteeing the same functionality of commercial equipments. Lettuce seeds (Lactuca sativa L.) were used to test the new equipment for a germination assay. It was compared with another one already extant in the lab and calibrated. Construction details are given so that other equipments could be manufactured.
\end{abstract}

KEY WORDS: Incubator; Recycling; Re-use; Germination tests.

\footnotetext{
Graduação em andamento em Licenciatura e Bacharelado em Ciências Biológicas. Centro Universitário Hermínio Ometto de Araras (UNIARARAS), Brasil.

** Pós-doutorado em Ecologia Vegetal pela Universidade de Aveiro (Portugal). Docente Assistente de Botânica do Centro Universitário Hermínio Ometto (UNIARARAS), Brasil. E-mail: pedroso@uniararas.br
} 


\section{INTRODUÇÃO}

Em estudos biológicos, muitas investigações são realizadas em laboratórios. Tais locais devem ser estruturados às necessidades do ambiente de pesquisa de docentes e alunos. Isto visa permitir o desenvolvimento de investigações científicas nas diferentes áreas do conhecimento biológico e nas interfaces com as demais áreas de conhecimento. Por meio destas adequações obtêm-se, portanto, locais capazes de dar suporte a estudos acadêmicos em nível de graduação (iniciação científica) e pós-graduação (mestrados e doutorados) (GASPER, 2011).

Uma das áreas que apresenta amplo interesse científico-biológico atual é a germinação de sementes. A germinação é uma sequência de eventos fisiológicos influenciados por fatores externos (ambientais) e internos (dormência, inibidores e promotores da germinação), sendo que cada fator pode atuar por si ou em interação com os demais (NASSIF et al., 2015). Contudo, várias investigações realizadas apontam que os principais fatores que afetam a germinação; são a temperatura e a luz (LABOURIAU, 1983).

O processo germinativo envolve várias etapas e cada uma delas exige determinada temperatura para que tal fenômeno biológico se processe de maneira mais rápida e eficiente. Assim, os efeitos da temperatura sobre a germinação refletem apenas a consequência global, não havendo um coeficiente único que caracterize a germinação (POPINIGIS, 1977).

A temperatura afeta a capacidade de germinação e a taxa em que esta ocorre. As sementes têm capacidade de germinar sob a faixa de temperatura característica da espécie, mas o tempo necessário para ser alcançada a máxima porcentagem de germinação varia com a temperatura (BEWLEY; BLACK, 1994).

Existe um consenso entre os pesquisadores no qual a temperatura não apresenta um valor específico para germinação, mas pode ser expressa em termos das temperaturas, mínima, máxima e ótima. A temperatura ótima é definida sendo aquela em que ocorre o máximo de germinação em tempo relativamente curto (NOVEMBRE, 1994).

Por sua vez, a luz regula a germinação por meio da molécula do fitocromo. As sementes que germinam na presença de luz são chamadas fotoblásticas positivas, 
enquanto aquelas nas quais a germinação é inibida pela luz são chamadas fotoblásticas negativas (VÁSQUES-YANES; OROZCO-SEGOVIA, 1993; BEWLEY; BLACK, 1994).

Dessa forma, aparelhos como incubadoras B.O.D. (Biochemical Oxygen Demand) que permitem o controle experimental de fotoperíodos e de constâncias e/ ou variações na temperatura são de fundamental importância para estudos fisiológicos germinativos. Empregadas principalmente em estudos e produção de sementes e mudas, tais câmaras de germinação oferecem ao pesquisador a possibilidade de simular, neste equipamento, as características térmicas e de inserção de luz tanto do dia, quanto da noite (SPALABOR, 2015).

Durante pesquisas realizadas com as sementes e mudas, o pesquisador necessita de dados que podem ser adquiridos apenas no período noturno ou vice e versa. Com isso, ele pode por meio de uma incubadora tipo B.O.D. simular as características gerais de cada período independentemente de qual esteja ocorrendo fora dela (SPALABOR, 2015).

Sob este aspecto, ressalta-se que para a realização de práticas laboratoriais, muitas vezes são caros os aparelhos necessários para pesquisas (POSSOBOM et al., 2003). Entretanto, na falta deles, é possível, de acordo com a realidade de cada local de ensino, que o professor e/ou alunos; realizem adaptações a partir de materiais existentes (CAPELETTO, 1992) e, ainda, utilizem materiais de baixo custo e de fácil acesso para a construção de equipamentos que se fazem necessários no ambiente laboratorial (LABURÚ; FERREIRA, 1996).

De encontro a esta temática, está o fato de que o avanço tecnológico tem causado o descarte de equipamentos eletrônicos em um curto espaço de tempo, tornando este tipo de lixo um problema cada vez mais aparente na sociedade atual (SILVA et al., 2014).

Quando não descartado adequadamente, o lixo eletrônico pode causar sérios danos à saúde e ao meio ambiente e atualmente há uma grande escassez de empresas especializadas na separação e reaproveitamento desses materiais, aumentando a importância da reciclagem do lixo tecnológico (SILVA et al., 2014). Dessa forma, a reutilização e reciclagem de "resíduos eletrônicos" vêm de encontro à necessidade atual da sociedade e demonstra a importância do desenvolvimento de projetos capazes de minimizar os efeitos das atividades antropogênicas sobre o meio ambiente natural. 
Assim, trabalhos como o presente, que visam construir aparelhos laboratoriais por meio da reutilização de materiais eletrônicos que se caracterizariam como lixo, torna-se importante ambientalmente, ainda mais; quando o produto final dessa reutilização for passível de ser utilizado para ensino e pesquisa.

$\mathrm{O}$ presente trabalho teve por objetivo construir, testar a funcionalidade e a viabilidade econômica de uma incubadora B.O.D. construída a partir de materiais reutilizados e reciclados, para uso em pesquisas pré-germinativas para os níveis de graduação e pós-graduação.

\section{MATERIAL E MÉTODOS}

Os componentes para a construção do equipamento foram obtidos, em parte, no centro de reciclagem de materiais localizado na cidade de Rio Claro (SP).

Foi adquirido um refrigerador que recebeu em seu interior iluminação e aquecimento, e conjuntamente um controlador comercial de temperatura, sistema de ventilação forçada e um temporizador para controle do fotoperíodo (Figura 1).

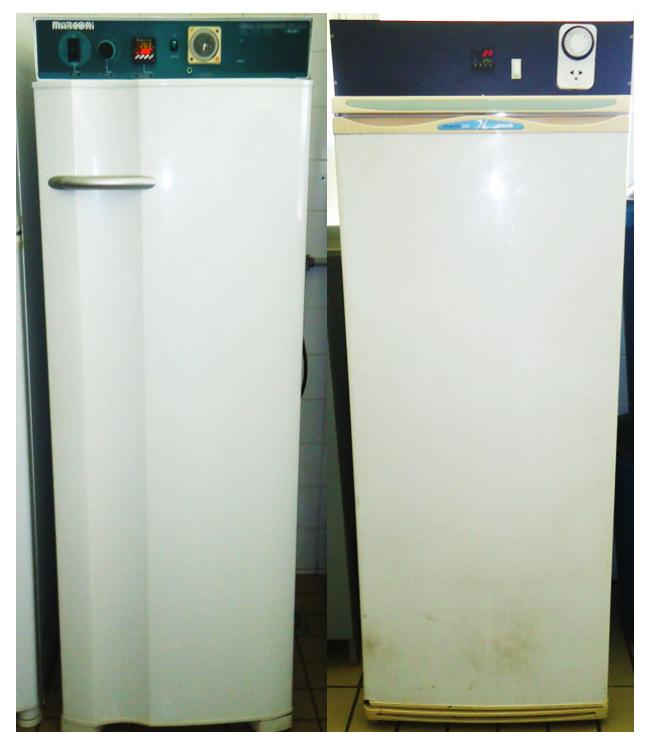

Figura 1. Câmaras de germinação tipo B.O.D. Direita: industrializada (Marconi $\left.{ }^{\circledR}\right)$. Esquerda: construída com material reciclado. 
Todos os investimentos realizados para a construção da incubadora se encontram na Tabela 1 .

Tabela 1. Listagem de todos os componentes utilizados na construção da incubadora tipo B.O.D., contendo: custo, origem de cada item e a soma total dos valores empregados

(Continua)

\begin{tabular}{|c|c|c|c|}
\hline \multirow[t]{2}{*}{ ITEM } & \multirow[t]{2}{*}{ QUANTIDADE } & \multicolumn{2}{|c|}{ PREÇO R\$ } \\
\hline & & novo & usado \\
\hline Geladeira 310 litros & 1 & & 160 \\
\hline Controlador contemp ctm 45 & 1 & & 50 \\
\hline Cooler Ventilador $80 \times 80 \times 25 \mathrm{~mm}$ & 2 & & 6 \\
\hline Cooler Ventilador 120 × 120 × 25 mm & 2 & 20 & \\
\hline Timer temporizador analógico & 1 & & 10 \\
\hline $\begin{array}{l}\text { Resistência níquel-cromo, espiral para chocadeira, } 200 \mathrm{w} \\
110 \mathrm{v}\end{array}$ & 1 & & 20 \\
\hline Isoladores de porcelana tipo roldana: 18 x $20 \mathrm{~mm}$ & 8 & & 10 \\
\hline Conector sindal de porcelana & 1 & 8 & \\
\hline Contator bobina $110 \mathrm{v}$, ui $600 \mathrm{v}$ ith $10 \mathrm{a}$ cod ca2dn1319 & 1 & & 20 \\
\hline Termopar tipo J $4 \mathrm{~mm}$ & 1 & 20 & \\
\hline Reator Eletrônico Rcg Re 220 - 2 x 15/20 Watts Bivolt & 3 & & 0 \\
\hline Lâmpada Fluorescente tubular T10 20 w luz branca & 3 & 18 & \\
\hline Lâmpada Fluorescente tubular T8 15 w luz branca & 3 & & 0 \\
\hline Soquetes lâmpada fluorescente T8 T10 & 12 & & 0 \\
\hline Fonte at $250 \mathrm{w}$ bivolt & 1 & & 5 \\
\hline Fio Paralelo $1.00 \mathrm{~mm}$ x $1 \mathrm{~m}$ & 18 & 15 & \\
\hline Fio Flexível $1.50 \mathrm{~mm}$ x $1 \mathrm{~m}$ & 2 & 2 & \\
\hline Cabo PP 3 x $150 \mathrm{~mm}$ & 2 & & 0 \\
\hline Fita adesiva isolante $19 \mathrm{~mm} \times 20 \mathrm{~m}$ branca & 1 & 6 & \\
\hline Fita adesiva isolante $19 \mathrm{~mm} \times 20 \mathrm{~m}$ preta & 1 & 6 & \\
\hline Parafuso para madeira bicromatizado $3 \mathrm{~mm}$ x $20 \mathrm{~mm}$ & 16 & 2 & \\
\hline Parafuso Cabeça Panela 3 mm x 15 mm & 40 & 3 & \\
\hline Parafuso Cabeça hexagonal $3 \mathrm{~mm} \times 15 \mathrm{~mm}$ & 14 & 2 & \\
\hline Parafuso Cabeça hexagonal $3 \mathrm{~mm}$ x $30 \mathrm{~mm}$ & 2 & & 0 \\
\hline Porca Cromada Rosca $4 \mathrm{~mm}$ & 26 & 2 & \\
\hline Arruela Lisa - Aço Inox 13 mm & 32 & 2 & \\
\hline
\end{tabular}


(Conclusão)

\begin{tabular}{|c|c|c|c|}
\hline \multirow[t]{2}{*}{ ITEM } & \multirow[t]{2}{*}{ QUANTIDADE } & \multicolumn{2}{|c|}{ PREÇO R\$ } \\
\hline & & novo & usado \\
\hline Arruela Lisa - Aço Inox $9 \mathrm{~mm}$ & 8 & 1 & \\
\hline Varão roscado $4 \mathrm{~mm}$ x $1000 \mathrm{~mm}$ & 1 & 3 & \\
\hline Acrílico $34 \mathrm{~cm} \times 15 \mathrm{~cm} \mathrm{x} 4 \mathrm{~mm}$ & 2 & & 0 \\
\hline Acrílico $6 \mathrm{~cm} \times 6 \mathrm{~cm} \times 4 \mathrm{~mm}$ & 6 & & 0 \\
\hline Acrílico $53 \mathrm{~cm} \times 28 \mathrm{~cm} \mathrm{x} 4 \mathrm{~mm}$ & 1 & & 0 \\
\hline Madeira MDF $10 \mathrm{~mm} 30 \mathrm{~cm} \times 60 \mathrm{~cm}$ & 2 & 20 & \\
\hline Madeira MDF $10 \mathrm{~mm} 15 \mathrm{~cm} \mathrm{x} 60 \mathrm{~cm}$ & 2 & 10 & \\
\hline Madeira MDF $10 \mathrm{~mm} 30 \mathrm{~cm} \mathrm{x} 13 \mathrm{~cm}$ & 2 & 8 & \\
\hline SUBTOTAL & 110 & 321 & \\
\hline TOTAL & $\mathrm{R} \$ 431$ & & \\
\hline
\end{tabular}

Para a construção da incubadora foi idealizado e esquematizado um diagrama de montagem (Figura 2).

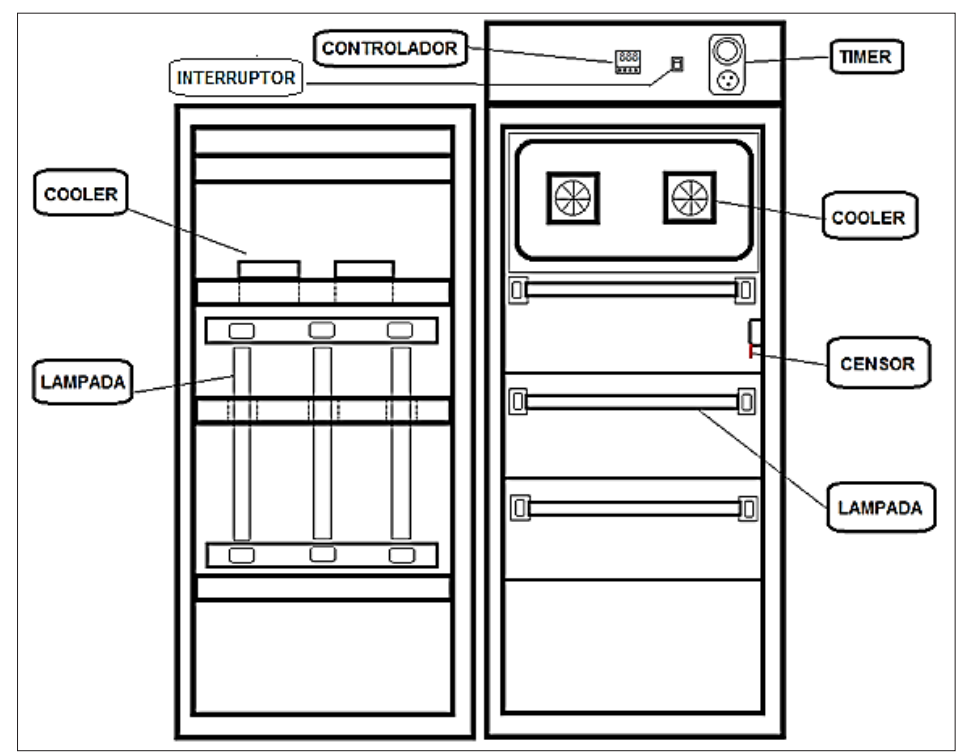

Figura 2. Diagrama de montagem utilizado para a construção da incubadora tipo B.O.D. Fonte: Os autores.

A seguir, por meio de esquema, mostra-se em detalhe o conjunto formado por 2 coolers de $120 \mathrm{~mm}$ x $120 \mathrm{~mm}$ e as roldanas de porcelana que sustentam a 
resistência de aquecimento (Figura 3).

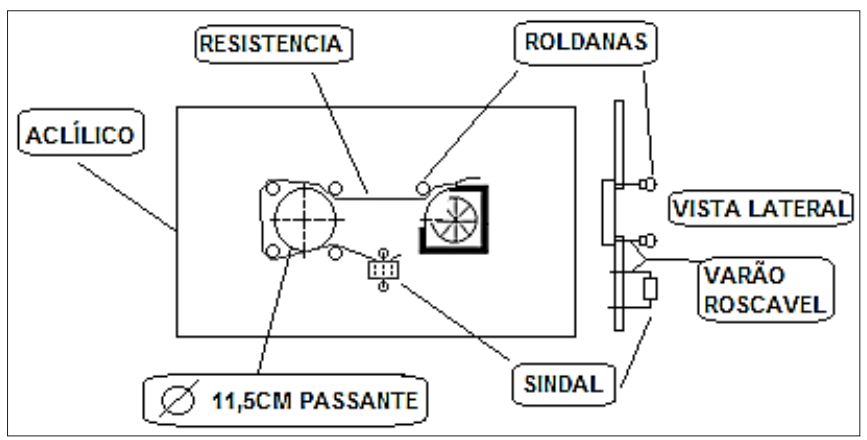

Figura 3. Esquema demonstrativo do conjunto composto por coolers, roldanas de porcelana e resistência de aquecimento, sistema responsável pela estabilização da temperatura interna da incubadora tipo B.O.D. Fonte: Os autores.

O conjunto fica sustentado em uma placa acrílica com medidas $28 \mathrm{~cm} \times 53$ cm x $4 \mathrm{~mm}$ com partes do varão roscável de medidas $100 \mathrm{~mm}$ x $4 \mathrm{~mm}$, presos com arruelas e porcas. A placa conta com dois furos circulares com $11,5 \mathrm{~cm}$ de diâmetro e permite que a ventilação forçada pelos coolers possa estabilizar a temperatura por meio do transporte de ar frio ou quente oriundos do congelador original da geladeira e da resistência de $200 \mathrm{~W}$ de potência que encontra-se ligada a um sindal de porcelana.

O painel fixado acima da geladeira é formado por placas de MDF de espessura $10 \mathrm{~mm}$ (Tabela 1), formando uma caixa retangular, presa com parafusos, com a finalidade de alojar os instrumentos de controle de temperatura e fotoperíodo (Figura 3).

No diagrama elétrico observa-se a proteção formada pelos contatores K2 e $\mathrm{K} 3$, onde evita que os dois comutem simultaneamente por alguma falha no equipamento (Figura 4). Nota-se a existência de três contatos ligados em paralelo em K3. Tal configuração é devido à corrente de partida do compressor da geladeira que chega ao valor de 15 Amperes. 


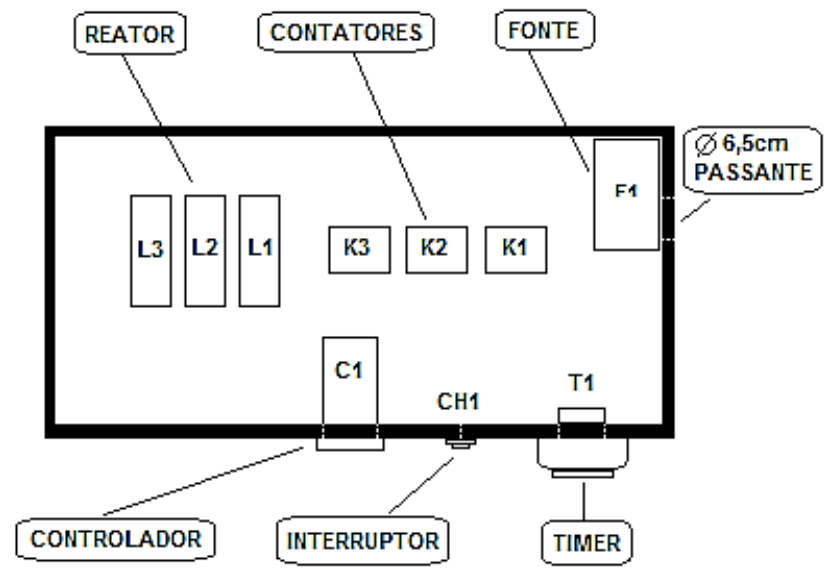

Figura 4. Painel montado e fixado sobre a "carcaça" da geladeira contendo os instrumentos de controle de temperatura e fotoperíodo da incubadora tipo B.O.D.

Fonte: Os autores.

Como os modelos de contator usados apresentam carga máxima de $10 \mathrm{Am}$ peres, para evitar a queima dos mesmos pela carga excessiva, foi realizada uma ligação em paralelo de três contatos normalmente abertos, dividindo a carga para a metade do valor máximo para cada contato (Figura 5).
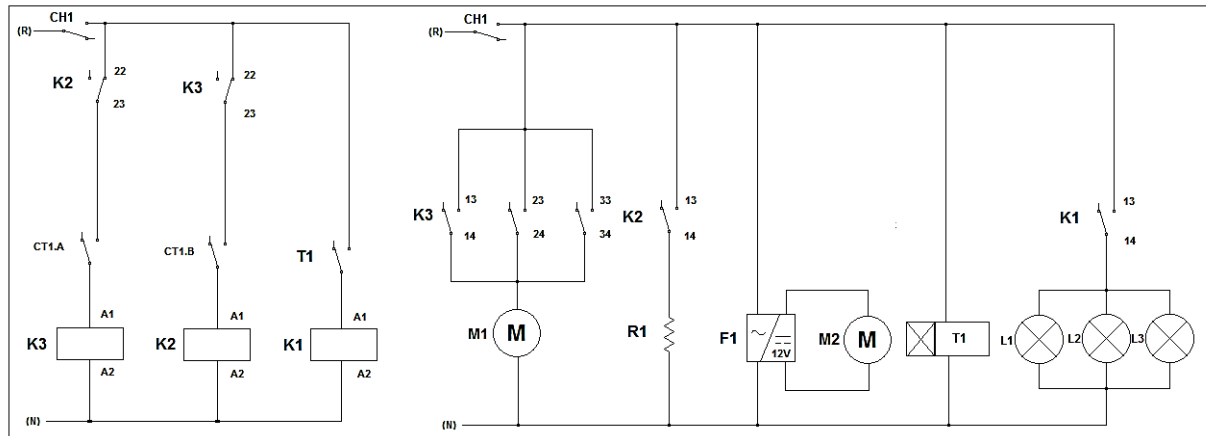

Figura 5. Diagrama elétrico da incubadora tipo B.O.D., evidenciando a proteção formada por contatores. $\mathrm{K} 1=$ contator $1 ; \mathrm{K} 2=$ contator $2 ; \mathrm{K} 3=$ contator 3; $\mathrm{C} 1 . \mathrm{A}=$ controlador saída 1 ; $\mathrm{C} 1 . \mathrm{B}=$ controlador saída 2; $\mathrm{CH} 1=$ interruptor geral; $\mathrm{L} 1=$ reator $1 ; \mathrm{L} 2=$ reator $2 ; \mathrm{L} 3=$ reator $3 ; \mathrm{M} 1=$ motor de geladeira; $\mathrm{M} 2$ = conjunto de coolers; $\mathrm{R} 1$ = resistência aquecimento.

Fonte: Os autores. 
Para o controle da temperatura foi usado em conjunto com o controlador; um sensor de temperatura classificado como tipo J. Sua faixa de operação se situa entre 0 a $760^{\circ} \mathrm{C}$, muito além do que é necessário para o perfeito funcionamento do B.O.D.

Para a verificação da correta calibração e funcionamento da incubadora, foram realizados testes comparativos de germinação pela utilização de cipselas da planta modelo experimental Lactuca sativa L. (alface).

Um primeiro lote de cipselas foi distribuído em grupos de 25 unidades, em quatro placas de Petri, previamente esterilizadas, forradas com duas folhas de papel de filtro e umedecidas com $10 \mathrm{~mL}$ de água destilada (BRASIL, 2009; BONIN et al., 2010). As placas foram mantidas em Câmara de Germinação B.O.D. (MA 403) (Marconi ${ }^{\circledR}$ ). Da mesma forma, o segundo lote foi submetido à germinação na incubadora B.O.D. construída. Nos dois casos, os lotes foram submetidos à temperatura de $25{ }^{\circ} \mathrm{C} \pm 2$ (EMBRAPA, 2002) e luz branca de lâmpadas fluorescentes a 40 $\mu \mathrm{mol} . \mathrm{m}^{-2} \cdot \mathrm{s}^{-1}$ ao nível da cipselas e deixadas até sua germinação (BONIN et al., 2010). O monitoramento do experimento foi diário (até sete dias) e cipselas com protusão radicial e curvamento geotrópico positivo foram consideradas germinadas (BRASIL, 2009). Os dados obtidos foram utilizados para o cálculo da Germinabilidade (G\%), do Índice de Velocidade de Germinação (IVG) (LABOURIAU; AGUDO, 1987) e do comprimento radicular (CR).

Para a análise estatística comparativa dos dados obtidos nas duas incubadoras tipo B.O.D. foi utilizado o teste de Liliefors para normalidade dos resíduos da ANOVA. Como essa pressuposição foi atendida para todas as medidas analisadas, para o experimento; foi aplicada a análise de variância (ANOVA), seguida pelo teste de Tukey a 5\% de significância (SOKAL; ROHLF, 1981), com o auxílio do aplicativo BioEstat 4 (AYRES et al., 2004).

\section{RESULTADOS E DISCUSSÃO}

A precisão das medidas está obviamente relacionada com a qualidade da construção de instrumentos/aparelhos. Essa qualidade é determinada pela cautela que se deve tomar em pontos importantes como o posicionamento e a fixação dos parafusos, com a qualidade da escalas e seu zeramento (LABURÚ; FERREIRA, 1996). 
Tal sugestão vem de encontro aos resultados estatísticos comparativos encontrados para as cipselas de alface para os quais os lotes comparados não apresentaram diferenças estatísticas significantes com relação à G\%, IVG e CR (Figura 6, Tabela 2), tanto para a B.O.D. MA 4003, quanto para a construída com material reciclado.
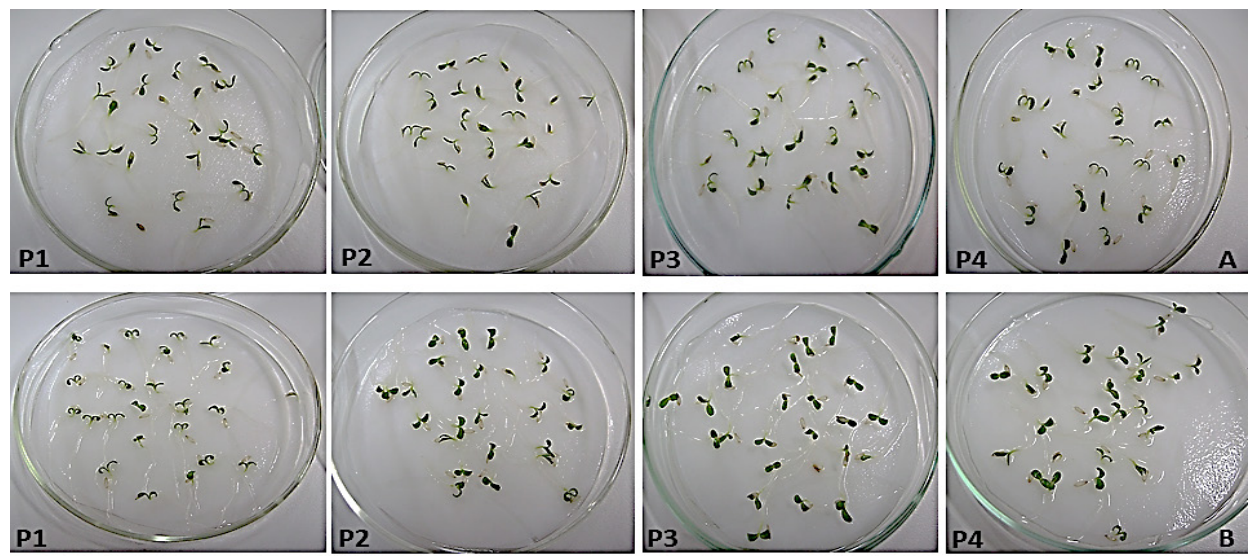

Figura 6. Testes de germinação com cipselas de Lactuca sativa L. (alface) realizados entre as incubadoras. B.O.D. construída com material reutilizado/reciclado (A); B.O.D. Marconi 시 (B). P1, P2, P3, P4 = ordenação das placas utilizadas para comparação.

Tabela 2. Resultados dos testes de germinação comparativos em cipselas de Lactuca sativa L. (alface) realizados entre as incubadoras B.O.D. Marconi ${ }^{\circledR}$ e a construída com material reutilizado/reciclado

\begin{tabular}{cccc}
\hline Incubadoras B.O.D & G\% & IVG & CR (cm) \\
\hline Marconi ${ }^{\circledR}$ & $25,0 \mathrm{~A}^{1}$ & $23,0 \mathrm{~A}$ & $3.91 \mathrm{~A}$ \\
Construída & $24,5 \mathrm{~A}$ & $22,7 \mathrm{~A}$ & $3.29 \mathrm{~A}$ \\
CV\% & 1,18 & 1,03 & 12,52 \\
DP & 0,58 & 0,41 & 0,74 \\
\hline
\end{tabular}

${ }^{1}$ Letras iguais na mesma coluna, não diferente estatisticamente entre si pelo teste de Tukey a $5 \%$.

A não diferença estatística indica que não há, portanto, diferenças na obtenção de resultados entre os dois equipamentos, evidenciando que a incubadora construída pode ser utilizada seguramente para o desenvolvimento de pesquisas baseadas em testes pré-germinativos. 
A reutilização de materiais para a construção da incubadora tipo B.O.D. permitiu uma reintrodução no sistema produtivo-acadêmico de uma parte da matéria (e da energia), que se tornaria lixo. Assim, os resíduos sólido-eletrônicos coletados, separados e processados foram usados como matéria-prima na manufatura do aparelho laboratorial, o que era feito anteriormente com matéria-prima virgem. Dentre os benefícios socioambientais de tais práticas, pode-se listar (RECICLAR, 2015):

- Menor comprometimento de recursos naturais;

- Diminuição da poluição do solo, água e ar;

- Melhoria da limpeza das cidades e da qualidade de vida das populações;

- $\quad$ Prolongamento da vida útil de aterros sanitários;

- Contribuição para a valorização da limpeza pública e para a formação de consciência ecológica;

- Estimulo à concorrência, uma vez que produtos gerados a partir dos reciclados são comercializados em paralelo àqueles gerados a partir de matérias-primas virgens. Esta última afirmação encontra subsídio no fato de que a construção da B.O.D. mostrou ser vantajosa, principalmente em relação ao seu custo. Em comparação com outros três modelos comerciais, observa-se que o custo final do equipamento resultou em aproximadamente $10 \%$ do modelo mais barato encontrado em um pregão da Internet (COMPRASNET, 2014) (Tabela 3).

Tabela 3. Comparação de componentes, estruturas, capacidade, potência e valores de mercado de incubadoras B.O.D. comumente encontradas no mercado e a construída com material reutilizado/reciclado

CARACTERÍSTICAS

DOS APARELHOS

\section{COMERCIAIS}

$\begin{array}{lccc}\text { CONSTRUIIDA } & \begin{array}{c}\text { TECNAL } \\ (\text { Mod. TE-402) }\end{array} & \begin{array}{r}\text { MARCONI } \\ \text { (MA 403) }\end{array} & \text { MICROLLAGOS }\end{array}$

$\begin{array}{ccccc}\text { Capacidade (L) } & 310 & 275 & 334 & 340 \\ \mathbf{N}^{\text {o. }} \text {. Lâmpadas } & 6 & 4 & 4 & \text { não definido } \\ \mathbf{N}^{\circ} \text {. Prateleiras } & 3 & 5 & 10 & 5 \\ \quad \text { Sensor } & \text { Tipo J } & \text { PT - } 100 & \text { PT - } 100 & \text { PT - } 100 \\ \text { Potência (W) } & 200 & 100 & 400 & 1200\end{array}$

Valor $(\mathbf{R} \$)$

431,0000

$4.460,0000$

$5.736,6700$

$5.736,6700$ 
O fato que mais dificultou o andamento do trabalho foi a aquisição de algumas peças; as mais trabalhosas foram as roldanas de porcelana. Atualmente tais roldanas foram substituídas por plástico no mercado. A saída foi procurar em desmanche de casas antigas. Infelizmente, as encontradas dessa forma são vendidas como itens de colecionador, atingindo altos valores.

\section{CONSIDERAÇOES FINAIS}

O ensino e o desenvolvimento de pesquisa em nível acadêmico realizado com parcos recursos e/ou desprovido de aparelhagem laboratorial especializada são prejudiciais à plena aprendizagem acadêmica e à formação de futuros pesquisadores, os quais, neste quadro, se tornam incapazes de realizar o "alargamento das fronteiras científicas", tal como preconizado e afirmado continuamente nos atuais cursos de Ciências Biológicas das universidades brasileiras.

Sob este aspecto, vale ressaltar que inúmeras Unidades de Ensino Superior (UES) apresentam cursos (como os Bacharelados em Engenharias: Ambiental, Elétrica, Materiais e Mecânica) capazes de permitir a construção de aparelhagens laboratoriais de baixo custo, pela reutilização e reciclagem de materiais, demonstrando compromisso com a preservação do meio ambiente, como o demonstrado neste trabalho, pela construção eficiente da Câmara de Germinação tipo B.O.D.

Assim, mesmo UES privadas, que lutam constantemente para manter-se no mercado e realizar formação superior de qualidade, poderiam desenvolver programas de iniciação científica junto a tais cursos, a fim de propiciar aprendizagem prática discente e a construção de aparelhos de baixo custo. Tal ação provavelmente permitiria melhorias e incrementos no suporte laboratório-educacional tanto em nível de graduação, quanto de pós-graduação, com menores custos e eficiência pedagógica.

Além disso, a economia realizada neste setor de gastos universitário poderia permitir que os recursos poupados pudessem ser usados para melhor remuneração e capacitação de docentes, aumento das verbas de materiais de consumo laboratoriais, desenvolvimento de maior número de projetos de extensão à comunidade $\mathrm{e}$ 
folga orçamentária para a realização dos demais trâmites administrativos universitários.

\section{REFERÊNCIAS}

AYRES, M.; AYRES JR., M.; AYRES, D. L.; DOS SANTOS, A. S. BioEstat 4: aplicações estatísticas nas áreas das ciências biológicas e médicas. Belém: Sociedade Civil Mamirauá, Brasília CNPq, xii, 2004.

BEWLEY, J. D.; BLACK, M. Seeds: physiology of development and germination. Plenum Press, New York, 1994.

BONIN, M. P.; PEDROSO-DE-MORAES, C.; MARTINI, G. A.; VERDOLIN-BENEDITO, P.; SOUZA-LEAL, T. Avaliação dos tratamentos pré-germinativos em diferentes concentrações de GA3 na germinação de Alcantarea imperialis (Vell.) Harms. Scientia Plena, v. 6, n. 5, p. 1-4, 2010.

BRASIL. Ministério da Agricultura, Pecuária e Abastecimento. Regras para Análise de Sementes (RAS). Ministério da Agricultura, Pecuária e Abastecimento. Secretaria de Defesa Agropecuária. Brasília: Mapa/ACS, 2009.

COMPRASNET. Pregão eletrônico. Disponível em: < http://www.comprasnet.gov. br/livre/Pregao/propostas.asp?ipgCod=7926408> . Acesso em: 10 ago. 2014.

EMBRAPA. Empresa Brasileira de Pesquisas Agropecuárias. Germinação de sementes de alface. Disponível em: < http://www.cnph.embrapa.br/paginas/serie_documentos/publicacoes2002/ct_29.pdf> Acesso em: 04 abr. 2015.

GASPER, A. L. Laboratório de Botânica. Disponível em: < http://www.furb.br/ botanica/>. Acesso em: 06 ago. 2011.

LABOURIAU, L. G. A germinação das sementes. Washington: OEA, 1983.

LABOURIAU, L. G.; AGUDO, M. On the physiology of seed germination in Salvia bispanica L. Temperature effects. Anais da Academia Brasileira de Ciências, v. 59, p. 37-56, 1987. 
LABURÚ, C. E.; FERREIRA, N. C. Construindo um esferômetro e cilindrometro (equipamentos de baixo custo). Caderno Brasileiro de Ensino de Física, v. 13, n. 2, p. 165-171, 1996.

NASSIF, S. M. L.; VIEIRA, I. G.; FERNANDES, G. D. Fatores Externos (ambientais) que Influenciam na Germinação de Sementes. Informativo Sementes IPEF - Arborizar - Bioengenharia Ambiental. Disponível em: < http://www.ipef.br/tecsementes/ germinacao.asp >. Acesso em: 27 mar. 2015.

NOVEMBRE, A. D. L. C. Estudo da metodologia para a condução do teste de germinação em sementes de algodão (Gossypium birsutum L.) deslintadas mecanicamente. 1994. 133p. Tese (Doutorado em Agronomia) - Escola Superior de Agricultura Luiz de Queiroz, Piracicaba.

POPINIGIS, F. Fisiologia da semente. Brasília: AGIPLAN, 1977.

POSSOBOM, C. C. F.; OKADA, F. K.; DINIZ, R. E. S. Atividades práticas de laboratório no ensino de biologia e ciências: relato de uma experiência. In: GARCIA, W. G.; GUEDES, A. M. (Orgs.). Núcleos de ensino. São Paulo: Unesp, Pró-Reitoria de Graduação, 2003. p. 113-123. Disponível em: <www.unesp.br/prograd/nucleo2003/ index2002.php>. Acesso em: 17 mar. 2015.

RECICLAR. Materiais recicláveis: preservação ambiental. Disponível em: < http:// www.reciclarbrasil.com.br/meioambiente.asp > . Acesso em: 04 abr. 2015.

SILVA, A.; GUMERSINDO, D.; MECENAS, J.; RAMOS, V.; ARAÚJO, P. J. P. Reutilização do lixo eletrônico da Universidade Tiradentes. Cadernos de Graduação - Ciências Exatas e Tecnológicas Unit, v. 2, n. 1, p. 63-70, 2014.

SOKAL, R. R.; ROHLF, F. J. Biometry. New York: W. H. Freeman, 1981.

SPALABOR. Equipamentos para laboratórios: câmara de germinação. Disponível em: <http://www.splabor.com.br/blog/camara-de-germinacao-2/camara-de-germinacao-com-fotoperiodo-simula-as-caracteristicas-dos-periodos-do-dia/\# more2827>. Acesso em: 17 mar. 2015. 
VÁQUES-YANE, S; OROZCO-SEGOVIA, A. Patterns of seed longevity and germination in the tropical rain Forest. Annual Review of Ecology and Systematics, v. 24, n. 1, p. 69-87, 1993.

Recebido em: 24/04/2015

Aceito em: 17/05/2017 